\title{
Instituições Residenciais Brasileiras para Idosos e Condições Psicológicas e Cognitivas de Residentes
}

\author{
Andréia Schmidt ${ }^{1}$ \\ ${ }^{1}$ Universidade de São Paulo, SP, Brasil.
}

\author{
Raísa Abrantes Penna ${ }^{1}$ \\ ${ }^{1}$ Universidade de São Paulo, SP, Brasil.
}

\begin{abstract}
Resumo: $\mathrm{O}$ aumento da população idosa no Brasil tem feito crescer a demanda por cuidados de longa duração oferecidos por instituições de longa permanência para idosos (Ilpi). A literatura apresenta caracterizações de Ilpi em cidades ou regiões específicas, mas uma visão geral dessas instituições e de seus residentes, especialmente em termos de características psicológicas e cognitivas, pode ajudar psicólogos a compreenderem as necessidades desses idosos e a planejar intervenções. O objetivo desta revisão integrativa é caracterizar Ilpi brasileiras, em termos de condições de funcionamento e de oferta de serviços, bem como de funções psicológicas e cognitivas de seus residentes, com fundamentação na literatura científica. Por meio de buscas nas bases SciELO, PePSIC e Periódicos Capes, foram selecionados nove artigos que caracterizam Ilpi brasileiras e 19 estudos que qualificam as condições psicológicas e cognitivas de residentes. Os artigos caracterizam 41 Ilpi de quatro do país. A maioria dessas instituições eram filantrópicas e recebiam idosos de ambos os sexos (majoritariamente mulheres), com preferência a pessoas independentes para atividades de vida diária. Os ambientes físicos eram compatíveis com a legislação, mas as rotinas eram rígidas e havia pouca oferta de atividades de lazer, o que contribuía para a baixa autonomia dos residentes. Constataram-se quadros reduzidos de funcionários, majoritariamente profissionais de saúde e cuidadores. A depressão foi a condição mais estudada, com prevalência média de $50 \%$ em residentes. A prevalência de declínio cognitivo variou entre $45 \%$ e $86 \%$. Discute-se a necessidade de profissionais preparados para o trabalho junto a essa população, especialmente psicólogos capazes de intervir sobre o sofrimento psíquico de residentes.
\end{abstract}

Palavras-chave: Instituições de Longa Permanência para Idosos, Desordens Psiquiátricas, Gerontologia, Idosos Institucionalizados.

\section{Brazilian Long-Term Care Institutions and Psychological and Cognitive Conditions of Residents}


environment compatible with the legislation, all ILPIs had rigid routines and little time for leisure activities, contributing to the residents' low autonomy, and had reduced staff mostly health professionals and caregivers. Depression had an average prevalence of $50 \%$, while the prevalence of cognitive decline ranged from $45 \%$ to $86 \%$. We need professionals prepared to work with this population, especially psychologists capable of intervening on the resident's psychological suffering.

Keywords: Long-Term Institutions for the Elderly, Psychiatric Disorder, Gerontology, Institutionalized Elderly.

\title{
Los Hogares para Ancianos en Brasil y las Condiciones Psicológicas y Cognitivas de sus Residentes
}

\begin{abstract}
Resumen: El aumento de la población adulta mayor en Brasil ha ocasionado una mayor demanda de cuidados que ofrecen los hogares para ancianos (HA). La literatura presenta caracterizaciones de HA en ciudades o regiones específicas, y la visión general de estos establecimientos y sus residentes, especialmente de sus características psicológicas y cognitivas, pueden ayudar a los psicólogos a comprender las necesidades de esta población y a planear intervenciones. Esta revisión integrativa pretende evaluar los HA en Brasil en cuanto a condiciones de funcionalidad y a oferta de servicios, así como la salud psicológica y cognitivas de los residentes. A partir de la búsqueda de los datos en las bases SciELO, PePSIC y Periódicos Capes, se han seleccionado nueve artículos que evaluaban los HA brasileños y 19 estudios que caracterizaban las condiciones psicológicas y cognitivas de los residentes. Los artículos analizaron 41 HA de cuatro regiones del país. La mayoría de estos establecimientos era filantrópica y atendía a los adultos mayores de ambos sexos (la mayoría mujeres), con el requisito de que estuviesen aptos para realizar las actividades diarias. El ambiente físico estaba compatible con la legislación, pero las rutinas eran rígidas y había poca oferta de las actividades de ocio, lo que les aportaba a los residentes muy poca autonomía. Se contaba con un reducido número de trabajadores cuya mayoría era profesionales de la salud y cuidadores. La depresión fue la enfermedad más estudiada, con una prevalencia media del 50\%. La prevalencia de disminución cognitiva osciló entre el $45 \%$ y el $86 \%$. Esto evidencia la necesidad de capacitar a los profesionales para el trabajo con las personas mayores, en especial los psicólogos capaces de intervenir en el sufrimiento psíquico de los residentes.
\end{abstract}

Palabras clave: Hogares para Ancianos, Desórdenes Psiquiátricos, Gerontología, Ancianos Institucionalizados.

\section{Introdução}

Segundo o Estatuto do Idoso (Lei no 10.741/2003), no Brasil são consideradas idosas as pessoas com 60 anos ou mais. Nas últimas décadas, a população idosa tem aumentado no país, especialmente em função da queda rápida e contínua dos índices de fecundidade e da queda da mortalidade (Ervatti, Borges, \& Jardim, 2015). Estima-se que no período de 2012 a 2022 as taxas de crescimento da população idosa no país serão de mais de $4 \%$ ao ano. Em 2018 havia 19,2 milhões (9,2\%) de pessoas com 65 anos ou mais no Brasil e espera-se que em 2060 esse número chegue a 58,2 milhões, ou seja, $25,5 \%$ da população (IBGE, 2018). A população mundial também tem envelhecido rapidamente e estima-se que entre 2015 e 2050 haja um aumento de 900 milhões a 2 bilhões de pessoas com 60 anos 
ou mais, quase dobrando dos atuais $12 \%$ para $22 \%$ (World Health Organization [WHO], 2015).

Nos países em desenvolvimento como o Brasil, ocorreram avanços normativos e institucionais na proteção da velhice, como a garantia de uma renda mínima à população idosa. Entretanto, também é necessário que a velhice seja associada a uma vida ativa, saudável e bem cuidada, por meio da provisão de serviços de saúde e de cuidados formais (Camarano \& Mello, 2010b). A Organização Mundial de Saúde (OMS) (WHO, 2005) tem empregado o termo "envelhecimento ativo", que se refere ao "processo de otimização das oportunidades de saúde, participação e segurança, com o objetivo de melhorar a qualidade de vida à medida que as pessoas ficam mais velhas" (p. 13). Nesse sentido, o envelhecimento da população intensifica a necessidade de assistência aos idosos, devido às mudanças nos arranjos familiares, à mudança do papel social da mulher nas últimas décadas (tida tradicionalmente como a cuidadora preferencial dos membros dependentes da família) e às taxas de fecundidade abaixo do nível de reposição (Camarano \& Mello, 2010a).

De acordo com Carlomanho, Soares e Carvalho (2013), o avanço da idade pode gerar o declínio progressivo e natural das funções motoras e cognitivas. Os idosos estão mais expostos a doenças e agravos não transmissíveis (Camarano \& Mello, 2010b) e, por conta disso, há o predomínio de doenças crônicas não transmissíveis e declínio cognitivo, os quais podem comprometer a funcionalidade do idoso e, consequentemente, aumentar sua dependência e demanda por cuidado (Aires, Paz, \& Perosa, 2009). Considerando o contexto mais amplo do envelhecimento, que abrange não apenas aspectos biológicos, mas também sociais e econômicos, é necessária uma articulação entre o Estado, as famílias e o setor privado a fim de que se possam prover os cuidados necessários à população idosa brasileira, especialmente os cuidados de longa duração (Camarano \& Mello, 2010a).

Os cuidados de longa duração podem ser oferecidos pelos familiares, ou seja, de maneira informal, ou por meio do cuidado formal. O cuidado formal envolve o atendimento integral ao idoso em Instituições de Longa Permanência para Idosos (Ilpi), centros-dia, hospitais-dia e/ou em domicílio, e é oferecido por profissionais tanto do setor privado quanto do público (Camarano \& Mello, 2010a). As Ilpi são instituições residenciais de caráter governamental ou não governamental, que têm por objetivo prover domicílio coletivo para pessoas com 60 anos ou mais em condição de liberdade, dignidade e cidadania (Agência Nacional de Vigilância Sanitária [Anvisa], 2005).

Em uma pesquisa do Instituto de Pesquisa Econômica Aplicada (Ipea, 2011) realizada entre 2007 e 2009, foram localizadas 3.548 Ilpi no território brasileiro, nas quais residiam 83.870 idosos. Esse número, no entanto, tende a crescer em função do aumento das necessidades de cuidado às pessoas idosas, do número reduzido de familiares ou pessoas com disponibilidade para o cuidado de pessoas mais velhas em situação de dependência, da escassez de serviços de apoio social formal de saúde e do alto investimento pessoal e financeiro requerido para cuidado domiciliar. Todos esses fatores contribuem fortemente para a institucionalização do idoso (Aires et al., 2009; Camarano \& Kanso, 2010).

Apesar de se constituir em uma alternativa de cuidado necessária, a institucionalização pode provocar isolamento, inatividade física e falta de estimulação cognitiva para o idoso por mantê-lo fora de seu convívio familiar e pelas mudanças provocadas na adaptação à nova rotina e ao ambiente da instituição. A literatura relata que a institucionalização favorece a perda de autonomia e de identidade, uma vez que o idoso deve se adaptar à instituição de forma a mudar seus hábitos e rotinas (Jesus, Sena, Meira, Gonçalves, \& Alvarez, 2010). Além disso, é fundamental considerar que os fatores socioeconômicos estão diretamente relacionados não apenas à institucionalização em si, mas principalmente ao tipo de instituição em que o idoso será abrigado: de modo geral, os idosos negros, com baixa escolaridade, sem aposentadoria ou plano de saúde tendem a residir em Ilpi sem fins lucrativos, aquelas com maiores dificuldades de manutenção (Pinheiro, Holanda, Melo, Medeiros, \& Lima, 2016).

Além disso, observa-se a falta de profissionalização no funcionamento das Ilpi no Brasil, pois elas se organizam ainda no modelo filantrópico, o que acarreta uma prestação de assistência protecionista, que é pouco sensível à liberdade de escolha e às potencialidades das pessoas idosas. Esse contexto provoca o aumento da dependência do idoso, seu isolamento e a falta de perspectivas de uma vida ativa (Souza, Beneditti, Borges, Mazo, \& Gonçalves, 2011). Segundo Nóbrega, Leal, Marques e Vieira (2015), o contexto 
da instituição pode aumentar a vulnerabilidade a quadros depressivos, perda da autonomia e agravamento das patologias já existentes. Nesse contexto, o ambiente de institucionalização pode se tornar um fator de risco para problemas de ordem psicológica e cognitiva para os idosos.

Muitos artigos têm sido publicados analisando as condições de Ilpi no Brasil, mas, em geral, essas pesquisas abrangem um número pequeno de instituições de diferentes regiões do país. Analisar em conjunto essas pesquisas poderá ajudar a compreender, de forma mais geral, as condições de residência oferecidas por essas instituições. Além disso, integrar os dados produzidos sobre as condições psicológicas e cognitivas de idosos residentes em Ilpi, coletados em diferentes instituições e regiões do país, pode oferecer condições para que se verifique se há alguma regularidade nesses dados e se é possível relacionar as condições das Ilpi às condições dos residentes.

O objetivo desta revisão integrativa foi caracterizar Ilpi brasileiras, em termos de condições de funcionamento e de oferta de serviços, bem como funções psicológicas e cognitivas de seus residentes, com base na literatura científica. A questão norteadora deste estudo foi: quais são as características psicológicas e cognitivas de residentes em Ilpi no Brasil? Essas condições estão relacionadas de alguma forma às condições institucionais (ambientais, materiais, profissionais ou de rotina)? Para isso, foram revisados estudos que caracterizavam Ilpi brasileiras, assim como que caracterizavam idosos residentes nessas instituições.

\section{Método}

Foi realizada uma revisão integrativa, uma metodologia para revisão de literatura que permite a inclusão de estudos experimentais, não-experimentais, proposições teóricas e empíricas a fim de reunir, sintetizar e analisar resultados de estudos independentes sobre determinado assunto, numa determinada época (Souza, Silva, \& Carvalho, 2010).

\section{Procedimento}

Foi realizada uma busca nas bases de dados Scientific Eletronic Library Online (SciELO), Periódicos Eletrônicos de Psicologia (PePSIC) e Periódicos Capes, uma vez que nessas bases de dados há maior probabilidade de encontrar estudos realizados no Brasil. $\mathrm{O}$ acesso às bases de dados e a extração e seleção dos artigos ocorreu em setembro de 2016. As palavras-chave utilizadas foram: idosos, instituições, Ilpi, instituições de longa permanência para idosos, asilo e suas respectivas combinações.

Os critérios de inclusão foram: artigos que caracterizassem idosos brasileiros em relação à incidência de transtornos psiquiátricos, como depressão, ansiedade e comprometimento cognitivo, e os artigos que caracterizassem Ilpi brasileiras quanto a condições ambientais, corpo técnico e administrativo e rotina. Foram excluídos desta revisão os estudos que caracterizam a saúde geral, motora e funcional de idosos institucionalizados e não institucionalizados, pesquisas sobre cuidadores, sobre a percepção da família a respeito da institucionalização e do envelhecimento, avaliações de intervenções, validação de instrumentos e estudos que caracterizam Ilpi e seus residentes de outros países.

Foram encontrados 1.026 artigos nas bases de dados. Após exclusão das publicações duplicadas, restaram 626. Esses artigos passaram por três níveis de análise e seleção, todos baseados nos critérios de inclusão e exclusão descritos anteriormente: no primeiro nível, foram lidos os títulos dos artigos e excluídos todos aqueles que indicavam temas diferentes do foco deste estudo (e.g. estudos sobre ocorrência de quedas em idosos), procedimento ao fim do qual restaram 256 artigos. Na segunda rodada de análise, que continuou levando em conta os critérios de inclusão e exclusão, foram lidos os resumos dos artigos. Após essa leitura, restaram 61 artigos (195 excluídos). Na terceira rodada de análise, foi realizada a leitura completa dos artigos restantes e foram excluídos 34 artigos, de forma que restaram 28, incluídos nesta revisão. Desses artigos, 17 foram encontrados na base SciELO (aproximadamente 58\%), 10 na base Periódicos Capes (aproximadamente 37\%) e um no PePSIC (aproximadamente 3\%). Os artigos foram analisados com a utilização do instrumento apresentado por Souza et al. (2010) para revisões integrativas, com algumas adaptações.

Os artigos incluídos foram divididos em dois grupos. O primeiro grupo reúne nove artigos que caracterizam as Ilpi, conforme descreve a Tabela 1. 


\section{Tabela 1}

Estudos que caracterizaram Ilpi brasileiras.

\begin{tabular}{c}
\hline Autor, ano \\
\hline Angelo, Silva e Lima, 2011
\end{tabular}

Bestetti e Chiarelli, 2012

Carvalho, 2014

Cornélio e Godoy, 2013

Creutzberg et al., 2011

Faleiros e Morano, 2009

Título
Avaliação de ILPIs do
município de Olinda-PE

Planejamento criativo em Ilpi: Estudo de caso em Foz do Iguaçu - PR

Perfil das Ilpi situadas em uma capital do Nordeste

Perfil das Ilpi em uma cidade no Estado de São Paulo

Acoplamento estrutural das Ilpi com sistemas societais do entorno

Cotidiano e relações de poder numa Ilpi
Objetivos

Analisar a organização

e funcionamento das Ilpi do município de

Olinda-PE e perceber se as instituições atendem aos requisitos e normatização do Ministério da Saúde. Verificar as práticas gerenciais de uma

ILPI a fim de elaborar um planejamento gerontológico que demonstre, de maneira viável e criativa, uma possibilidade de contribuir com a qualidade do local.

Avaliar as condições de funcionamento dessas instituições e a qualidade da prestação de serviço aos idosos.

Descrever as características das instituições de longa permanência para idosos em Botucatu, SP, para o planejamento de ações que atendam às necessidades dos idosos, visando à melhoria da qualidade de vida.

Analisar como o sistema organizacional interno das Ilpi mantinha acoplamento estrutural com sistemas do entorno, como o econômico, familiar, o educacional e o de saúde.

Compreender as relações de poder institucional no cotidiano.
Instrumentos

Observação livre e participante; registro fotográfico; análise de documentos; questionário semiestruturado

Roteiros padronizados da Vigilância Sanitária da cidade de Maceió

Entrevistas; questionário; índice de Katz e de atividades de lazer
Observação de segunda ordem; entrevista semiestruturada

Registro de campo; observação direta; contato com os participantes; conversas com os internos e funcionários; diário de campo 


\begin{tabular}{|c|c|c|c|}
\hline Autor, ano & Título & Objetivos & Instrumentos \\
\hline Mansano-Schlosser et al., 2014 & $\begin{array}{c}\text { Idosos } \\
\text { institucionalizados: } \\
\text { Organização } \\
\text { cronológica das rotinas } \\
\text { diárias e qualidade do } \\
\text { sono }\end{array}$ & $\begin{array}{c}\text { Identificar a } \\
\text { percepção de idosos } \\
\text { institucionalizados } \\
\text { quanto à organização } \\
\text { cronológica das rotinas } \\
\text { diárias e quanto à } \\
\text { qualidade do sono. }\end{array}$ & $\begin{array}{l}\text { Questionário de } \\
\text { caracterização } \\
\text { sociodemográfica; } \\
\text { questionário de } \\
\text { avaliação do sono } \\
\text { e questionário } \\
\text { sobre organização } \\
\text { cronológica das } \\
\text { rotinas diárias }\end{array}$ \\
\hline Passos e Ferreira, 2010 & $\begin{array}{c}\text { Caracterização de } \\
\text { uma Ilpi e avaliação da } \\
\text { qualidade nutricional } \\
\text { da dieta oferecida }\end{array}$ & $\begin{array}{l}\text { Caracterizar uma Ilpi } \\
\text { com relação aos seus } \\
\text { aspectos estruturais, } \\
\text { sua dinâmica de } \\
\text { funcionamento e perfil } \\
\text { dos residentes. }\end{array}$ & $\begin{array}{l}\text { Fichas individuais } \\
\text { preenchidas pelo } \\
\text { Serviço Social; } \\
\text { prontuários e } \\
\text { prescrições médicas }\end{array}$ \\
\hline Yamamoto e Diogo, 2002 & $\begin{array}{l}\text { Os idosos e as } \\
\text { instituições asilares do } \\
\text { município de Campinas }\end{array}$ & $\begin{array}{c}\text { Caracterizar as } \\
\text { instituições asilares } \\
\text { destinadas a idosos do } \\
\text { município de Campinas } \\
\text { (SP), quanto aos seus } \\
\text { residentes, recursos } \\
\text { humanos e rotinas } \\
\text { realizadas. }\end{array}$ & $\begin{array}{c}\text { Visita aos locais; } \\
\text { entrevistas; } \\
\text { instrumento } \\
\text { construído com base } \\
\text { na Portaria no } 810 \\
\text { e no instrumento } \\
\text { utilizado por } \\
\text { outros autores }\end{array}$ \\
\hline
\end{tabular}

O segundo grupo, com 19 estudos, reúne os artigos que caracterizam os residentes das Ilpi em termos cognitivos e psicológicos, de forma direta ou indireta (e.g. por meio do rastreamento do uso de psicofármacos), conforme a Tabela 2 .

Tabela 2

Estudos de caracterização cognitiva e psicológica de idosos residentes em Ilpi.

\begin{tabular}{|c|c|c|c|}
\hline Autor, ano & Título & Objetivos & Instrumentos \\
\hline $\begin{array}{l}\text { Alencar, Bruck, Pereira, } \\
\text { Câmara, e Almeida, } 2012\end{array}$ & $\begin{array}{l}\text { Perfil dos idosos } \\
\text { residentes em uma } \\
\text { instituição de longa } \\
\text { permanência }\end{array}$ & $\begin{array}{l}\text { Caracterizar o perfil clínico- } \\
\text { funcional dos idosos que vivem } \\
\text { em uma instituição de longa } \\
\text { permanência localizada em Belo } \\
\text { Horizonte, Minas Gerais. }\end{array}$ & $\begin{array}{c}\text { Formulário; MEEM; } \\
\text { autorrelato do idoso ou } \\
\text { cuidador; } \\
\text { Índice de Katz; } \\
\text { Timed Up and Go } \\
\text { (TUG); GDS }\end{array}$ \\
\hline $\begin{array}{c}\text { Dantas, Bello, Barreto, e } \\
\text { Lima, } 2013\end{array}$ & $\begin{array}{l}\text { Capacidade funcional } \\
\text { de idosos com doenças } \\
\text { crônicas residentes em } \\
\text { Instituições de Longa } \\
\text { Permanência }\end{array}$ & $\begin{array}{c}\text { Descrever o desempenho } \\
\text { funcional e a presença de } \\
\text { doenças crônicas e agravos } \\
\text { em idosos residentes de } \\
\text { Instituições de Longa } \\
\text { Permanência em Recife, Brasil. }\end{array}$ & $\begin{array}{c}\text { Questionário; Medida } \\
\text { de Independência } \\
\text { Funcional; Escala de } \\
\text { Lawton e Brody; MEEM }\end{array}$ \\
\hline $\begin{array}{l}\text { Ferreira, Pinho, Pereira, } \\
\text { e Ferreira, } 2014\end{array}$ & $\begin{array}{l}\text { Perfil cognitivo de } \\
\text { idosos residentes em } \\
\text { Ilpi de Brasília-DF }\end{array}$ & $\begin{array}{l}\text { Avaliar o perfil cognitivo de } \\
\text { idosos institucionalizados por } \\
\text { meio de três instrumentos. }\end{array}$ & $\begin{array}{c}\text { MEEM; Teste de Trilhas } \\
\text { A; CDR }\end{array}$ \\
\hline
\end{tabular}




\begin{tabular}{|c|c|c|c|}
\hline Autor, ano & Título & Objetivos & Instrumentos \\
\hline $\begin{array}{l}\text { Fochat, Horsth, Sette, } \\
\text { Raposo, e Chicourel, } \\
2012\end{array}$ & $\begin{array}{l}\text { Perfil de utilização } \\
\text { de medicamentos } \\
\text { por idosos frágeis } \\
\text { institucionalizados na } \\
\text { Zona da Mata } \\
\text { Mineira, Brasil }\end{array}$ & $\begin{array}{l}\text { Identificar o perfil de utilização } \\
\text { de medicamentos por idosos } \\
\text { frágeis institucionalizados em } \\
\text { Juiz de Fora, cidade localizada } \\
\text { na Zona da Mata Mineira e } \\
\text { avaliar a presença de fármacos } \\
\text { potencialmente inadequados } \\
\text { e possíveis interações } \\
\text { medicamentosas. }\end{array}$ & $\begin{array}{l}\text { Fichas e receituários } \\
\text { dos residentes }\end{array}$ \\
\hline $\begin{array}{l}\text { Gautério, Santos, } \\
\text { Pelzer, Barros, e } \\
\text { Baumgarten, } 2012\end{array}$ & $\begin{array}{c}\text { Caracterização dos } \\
\text { idosos usuários de } \\
\text { medicação residentes } \\
\text { em instituição de longa } \\
\text { permanência }\end{array}$ & $\begin{array}{l}\text { Caracterizar os idosos residentes } \\
\text { em uma ILPI, quanto ao uso } \\
\text { de medicamentos e verificar a } \\
\text { existência de polifarmácia. }\end{array}$ & $\begin{array}{l}\text { Formulário; Avaliação } \\
\text { multidimensional do } \\
\text { Idoso }\end{array}$ \\
\hline $\begin{array}{c}\text { Gontijo, Penha, Fonseca, } \\
\text { e Augusto, } 2012\end{array}$ & $\begin{array}{l}\text { Estado cognitivo e } \\
\text { funcional de idosos } \\
\text { de uma instituição de } \\
\text { longa permanência } \\
\text { do município de } \\
\text { Divinópolis, Estado de } \\
\text { Minas Gerais, Brasil }\end{array}$ & $\begin{array}{l}\text { Qualificar capacidade funcional } \\
\text { e o estado cognitivo das } \\
\text { pessoas idosas que vivem } \\
\text { em uma instituição de longa } \\
\text { permanência. }\end{array}$ & $\begin{array}{l}\text { Registros do cadastro } \\
\text { dos participantes; } \\
\text { Indice Barthel; MEEM }\end{array}$ \\
\hline $\begin{array}{l}\text { Hartmann Jr., e } \\
\text { Gomes, } 2015\end{array}$ & $\begin{array}{l}\text { Sintomatologia } \\
\text { depressiva e } \\
\text { comprometimento } \\
\text { cognitivo de idosos } \\
\text { institucionalizados }\end{array}$ & $\begin{array}{l}\text { Descrever os sintomas } \\
\text { depressivos identificados pela } \\
\text { Escala de Depressão Geriátrica, } \\
\text { estabelecendo sua relação com } \\
\text { as perdas cognitivas de idosos } \\
\text { institucionalizados e domínios } \\
\text { depressivos. }\end{array}$ & Questionário; GDS \\
\hline $\begin{array}{c}\text { Jacinto, Aguiar, Franco, } \\
\text { Ribeiro, e Citero, } 2012\end{array}$ & $\begin{array}{l}\text { Estudo psicométrico } \\
\text { da Escala de Avaliação } \\
\text { de Demência e sua } \\
\text { aplicabilidade em } \\
\text { instituições de longa } \\
\text { permanência no Brasil }\end{array}$ & $\begin{array}{l}\text { Avaliar a sensitividade, a } \\
\text { especificidade diagnóstica } \\
\text { e a concordância da DRS } \\
\text { com o diagnóstico clínico de } \\
\text { DC (demência ou DC leve) } \\
\text { e comparar essas medidas } \\
\text { psicométricas com o escore de } \\
\text { MEEM. }\end{array}$ & $\begin{array}{c}\text { MEEM e DRS; } \\
\text { diagnóstico clínico }\end{array}$ \\
\hline Lampert e Rosso, 2015 & $\begin{array}{c}\text { Depressão em } \\
\text { idosas residentes em } \\
\text { instituição de longa } \\
\text { permanência }\end{array}$ & $\begin{array}{c}\text { Investigar a prevalência de } \\
\text { depressão e suas comorbidades } \\
\text { em uma Ilpi. }\end{array}$ & Prontuários \\
\hline $\begin{array}{l}\text { Leal, Apóstolo, Mendes, } \\
\text { e Marques, } 2014\end{array}$ & $\begin{array}{c}\text { Prevalência de } \\
\text { sintomatologia } \\
\text { depressiva e fatores } \\
\text { associados entre idosos } \\
\text { institucionalizados }\end{array}$ & $\begin{array}{l}\text { Conhecer a prevalência da } \\
\text { sintomatologia depressiva e } \\
\text { fatores sociodemográficos em } \\
\text { idosos institucionalizados. }\end{array}$ & Entrevista; GDS \\
\hline $\begin{array}{c}\text { Mattos, Carmo, Santiago, } \\
\text { e Luz, } 2014\end{array}$ & $\begin{array}{c}\text { Fatores associados à } \\
\text { incapacidade funcional } \\
\text { em idosos que vivem } \\
\text { em instituições de } \\
\text { longa permanência } \\
\text { no Brasil: um estudo } \\
\text { transversal }\end{array}$ & $\begin{array}{l}\text { Avaliar a capacidade funcional } \\
\text { de idosos institucionalizados e } \\
\text { realizar um estudo exploratório. } \\
\text { Analisar fatores associados } \\
\text { à dependência nesse grupo } \\
\text { populacional. }\end{array}$ & $\begin{array}{c}\text { Questionário } \\
\text { estruturado; } \\
\text { entrevistas; exames de } \\
\text { saúde; MEEM; ADL e } \\
\text { IADL; GDS }\end{array}$ \\
\hline
\end{tabular}


...continuação

\begin{tabular}{|c|c|c|}
\hline Autor, ano & Título & Objetivos \\
\hline $\begin{array}{l}\text { Mello, Haddad, e } \\
\text { Dellaroza, } 2012\end{array}$ & $\begin{array}{c}\text { Avaliação } \\
\text { cognitiva de idosos } \\
\text { institucionalizados }\end{array}$ & $\begin{array}{l}\text { Avaliação do estado cognitivo de } \\
\text { idosos residentes em Instituição de } \\
\text { Longa Permanência (ILP), detectando } \\
\text { possíveis perdas cognitivas, reafirmando } \\
\text { diagnóstico prévio de demência e } \\
\text { subsidiando o desenvolvimento de } \\
\text { atividades lúdico-pedagógicas. }\end{array}$ \\
\hline $\begin{array}{c}\text { Menezes, } \\
\text { Bachion, Souza, e } \\
\text { Nakatani, } 2011\end{array}$ & $\begin{array}{l}\text { Estudo longitudinal } \\
\text { dos aspectos } \\
\text { multidimensionais } \\
\text { da saúde de idosos } \\
\text { institucionalizados }\end{array}$ & $\begin{array}{l}\text { Analisar a evolução de aspectos } \\
\text { multidimensionais da saúde de idosos } \\
\text { institucionalizados no município de } \\
\text { Goiânia, no seguimento de dois anos, a } \\
\text { partir de aspectos sociodemográficos, } \\
\text { condições de saúde-doença, aspecto } \\
\text { psicoemocional e habilidades funcionais, } \\
\text { visando a subsidiar programas e ações } \\
\text { dirigidas a esses idosos. }\end{array}$ \\
\hline $\begin{array}{c}\text { Oliveira e } \\
\text { Novaes, } 2012\end{array}$ & $\begin{array}{c}\text { Uso de medicamentos } \\
\text { por idosos de } \\
\text { instituições de longa } \\
\text { permanência, Brasília- } \\
\text { DF, Brasil }\end{array}$ & $\begin{array}{l}\text { Descrever os perfis socioeconômico e } \\
\text { epidemiológico e o padrão de consumo } \\
\text { de medicamentos por idosos de Ilpi } \\
\text { de Brasília no intuito de expandir o } \\
\text { conhecimento sobre as características } \\
\text { e necessidades particulares dessa } \\
\text { população em constante crescimento. }\end{array}$ \\
\hline
\end{tabular}

Oliveira, Santos, e Pavarini, 2014

Reis, Torres, Araújo, Reis, e Novaes, 2009

$\begin{array}{cc}\text { Santiago e } & \begin{array}{c}\text { Sintomas depressivos } \\ \text { em idosos } \\ \text { Mattos, 2014 } \\ \text { institucionalizados }\end{array} \\ & \begin{array}{c}\text { Prevalência e } \\ \text { fatores associados à }\end{array} \\ \text { Silva, Sousa, } & \text { depressão entre idosos } \\ \text { Ferreira, e } & \text { institucionalizados: } \\ \text { Peixoto, 2012 } & \text { subsídio ao cuidado } \\ & \text { de enfermagem }\end{array}$

Smanioto e Haddad, 2013
Relação entre sintomas depressivos e a funcionalidade familiar de idosos institucionalizados

Rastreamento cognitivo de idosos institucionalizados no município de Jequié-BA

\section{Sintomas depressivos em idosos Prevalência e fatores associados à depressão entre idosos insticionalizados. de enfermagem}

Avaliação da farmacoterapia prescrita a idosos institucionalizados
Analisar a relação entre os sintomas depressivos com a funcionalidade familiar de idosos institucionalizados.

Avaliar o estado mental de idosos institucionalizados no município de Jequié, BA.

Analisar a prevalência de depressão em idosos institucionalizados e os fatores associados.

Avaliar a prevalência de sintomas de depressão em idosos institucionalizados e verificar possíveis fatores associados; verificar possíveis fatores associados que possam subsidiar a assistência de enfermagem.

Avaliar o perfil e a qualidade da farmacoterapia prescrita a idosos residentes em instituições de longa permanência situadas em Londrina-PR.
Instrumentos

Formulário; MEEM; Escala funcional de Atividades Básicas de Vida Diária

GDS; Escala de atividades básicas de vida diária de Katz

Questionário adaptado do Método Dáder de Acompanhamento farmacoterapêutico

Instrumento de caracterização socioeconômica; APGAR de família; GDS; entrevistas

MEEM; Protocolo com dados sociodemográficas e condições de saúde

$$
\begin{gathered}
\text { GDS; análise de } \\
\text { dados de projeto } \\
\text { anterior }
\end{gathered}
$$

GDS; questionário

$$
\begin{aligned}
& \text { Prontuário; } \\
& \text { informações } \\
& \text { fornecidas pelos } \\
& \text { profissionais } \\
& \text { responsáveis pelo } \\
& \text { cuidado dos idosos }
\end{aligned}
$$

Nota. GDS: Escala de Depressão Geriátrica; MEEM: Mini-Exame de Estado Mental; AD: Activities of Daily Living (índice Katz de funcionalidade); IADL: Instrumental Activities of Daily Living. 
Os artigos do primeiro grupo foram analisados em função da metodologia de estudo, participantes, instrumentos utilizados, local do estudo (região do país), resultados obtidos e discussão. A partir dessa caracterização, os resultados obtidos foram agrupados nas categorias de ambiente, rotina, profissionais e grau de dependência dos residentes. Já os artigos do segundo grupo foram analisados em função dos instrumentos, participantes, local da Ilpi e caracterização cognitiva e psicológica dos seus residentes, assim como os psicofármacos mais utilizados por eles. Após leitura completa de todos os artigos, as informações referentes a cada uma das categorias de análise foram agrupadas em tabelas para análise integrada. Para investigar o grau de dependência dos idosos, os dados de dois artigos (Angelo et al., 2011; Carvalho, 2014) foram agrupados pelas pesquisadoras para efeito de cálculo de porcentagem de categorias, uma vez que ambos os artigos utilizaram o mesmo instrumento. Esse tipo de análise não foi possível em outras categorias de análise em função da diversidade de formas de aferição das características das Ilpi adotadas pelos diversos autores.

\section{Resultados}

\section{Caracterização das Ilpi}

Os nove artigos analisados foram publicados entre 2002 e 2014 e caracterizavam as Ilpi quanto ao ambiente (aspectos estruturais e de organização), à rotina e ao funcionamento das instituições, além dos profissionais envolvidos. A maioria dos artigos (sete) tinha como objetivo a caracterização da organização e do funcionamento das Ilpi. Os outros dois caracterizaram as instituições participantes, mas tinham como objetivos principais a avaliação da qualidade do sono dos residentes e a avaliação da dieta oferecida nas instituições onde os estudos foram realizados (Mansano-Schlosser et al., 2014; Passos \& Ferreira, 2010). Nenhum artigo relacionou as condições ambientais e de rotina ao estado psicológico ou cognitivo dos residentes.

A quantidade de instituições analisadas por artigo variou de uma a nove. Ao todo, os artigos analisados trouxeram informações a respeito de 41 Ilpi. Essas instituições são localizadas nas regiões Nordeste (sete em Pernambuco, uma na Bahia, nove em Alagoas $-\mathrm{n}=17$ ); Centro-Oeste (uma no Distrito Federal $-\mathrm{n}=1$ ); Sudeste (uma no Rio de Janeiro, 17 em São Paulo - n = 18); e Sul (uma no Paraná, uma em Santa Catarina e três no Rio Grande do Sul $-\mathrm{n}=5$ ). Não foram encontrados artigos que caracterizassem Ilpi da região Norte.

Os instrumentos utilizados por essas pesquisas para a caracterização das instituições foram predominantemente entrevistas (quatro estudos) e questionários (três estudos). Quatro estudos também utilizaram observação direta (participante ou não), dois empregaram um instrumento padronizado (Avaliação para Ilpi da Anvisa) e um estudo fez uso das fichas individuais preenchidas pelo serviço social, prontuários e prescrições médicas dos residentes.

\section{As instituições}

Oito artigos fornecem informações a respeito do caráter jurídico das instituições (32 Ilpi) e sobre as suas fontes de renda (40 Ilpi). Sobre o caráter jurídico das instituições, 17 se declararam como instituições filantrópicas, 14 como instituições privadas e uma mista. Nenhuma instituição se declarou pública. O estudo de Creutzberg et al. (2011) caracterizou seis instituições e embora não tenha informado o caráter jurídico delas, descreveu que todas utilizavam a aposentadoria dos residentes e recebiam doações para sua manutenção, com pouca ou nenhuma participação do poder público nesse financiamento. Outras duas instituições também não tiveram seu caráter jurídico explicitado, mas, como forma de financiamento de despesas, uma declarou utilizar 50\% do Benefício de Prestação Continuada ou a aposentadoria dos residentes de um salário mínimo; e a outra, além da aposentadoria, mencionou auxílio da prefeitura, doações de roupas, móveis, cestas básicas e contribuições das famílias. Dentre as instituições filantrópicas, oito eram de caráter religioso.

Das Ilpi de caráter privado (14), quatro declararam utilizar a aposentadoria dos idosos para cobrir despesas de manutenção, mas duas também afirmaram receber doações de roupas, móveis, cestas básicas e contribuições dos familiares dos residentes.

O estudo de Creutzberg et al. (2011), que avaliou seis instituições, não fornece informações a respeito do caráter jurídico dessas instituições (filantrópica, privada, pública ou mista), porém, cita que todas utilizavam a aposentadoria dos idosos e recebiam doações de pessoas físicas e jurídicas. Quatro delas utilizavam verbas públicas, embora essas verbas representassem um percentual muito pequeno dos gastos realizados pela instituição. Duas tinham parte de seus funcioná- 
rios pagos por parceiros. Além disso, a realização de bazares, festas e rifas eram fundamentais para a arrecadação de dinheiro.

Dois artigos (Creutzberg et al., 2011; Yamamoto \& Diogo, 2002) trouxeram informações sobre os critérios de admissão estabelecidos por 12 Ilpi. No primeiro artigo foram avaliadas seis Ilpi, cinco das quais afirmaram aceitar idosos de qualquer nível de dependência, entretanto, três davam preferência para os idosos independentes para as atividades de vida diária. Em três instituições, a ausência de transtornos mentais e o respeito à vontade e à escolha do idoso para a institucionalização eram exigências para a admissão. Em quatro Ilpi, a ausência de dependência química, com exceção do tabaco, era uma exigência para aceitar o idoso.

Yamamoto e Diogo (2002) também avaliaram seis Ilpi, entre as quais três restringiam a idade de admissão para 55 a 65 anos. Duas utilizavam como critério o nível de dependência para atividades de vida diária, de forma que uma vedava o ingresso de pessoas extremamente dependentes, enquanto a outra não permitia o ingresso de pessoas dependentes. Três instituições tinham como critério restritivo à admissão a presença de distúrbios psiquiátricos e duas não aceitavam idosos agressivos ou com distúrbios de convivência social. O uso de álcool e o estado de terminalidade eram critérios restritivos em uma Ilpi. Em ambos os estudos, portanto, os critérios de admissão mais comuns estabelecidos pelas Ilpi estão relacionados ao nível de dependência para as atividades de vida diária, com preferência por idosos independentes. A presença de dependência química e de transtornos psiquiátricos foram fatores comumente referidos como causas de exclusão de residentes pelas instituições.

De acordo com os artigos pesquisados, é comum que as Ilpi tenham seus ambientes divididos em alas e pavilhões, nos quais os quartos são separados de acordo com o sexo dos residentes (no caso das instituições mistas) e com o grau de dependência. Foi relatada maior frequência de quartos coletivos do que de quartos individuais, assim como de banheiros de uso compartilhado.

De modo geral, em todas as instituições pesquisadas havia lavanderia, cozinha, depósito para alimentos, refeitório, sala com televisão e salas administrativas. Algumas instituições, citadas por dois artigos (Bestetti \& Chiarelli, 2012; Passos \& Ferreira, 2010), possuíam um espaço específico (salas) para a realização de fisioterapia, consultório médico e odontológico, farmácia e capela, entretanto, esses recursos estruturais não foram citados pela maioria dos estudos. Yamamoto e Diogo (2002) descreveram duas instituições que não possuíam espaços para atendimento médico e fisioterapêutico, motivo pelo qual esses atendimentos eram realizados no leito dos idosos. Salas de curativos, áreas de lazer e salas para atendimento psicológico, assim como a presença de psicólogos, não foram comuns (foram relatados em apenas um artigo). A existência de bibliotecas e serviços de corte de cabelo e barbearia também foi mencionada na descrição de um número muito reduzido de instituições.

O estudo de Creutzberg et al. (2011) levantou informações sobre as características ambientais das Ilpi que poderiam promover a manutenção da independência e da individualidade dos residentes, como a presença de campainhas nos leitos (observada em somente uma instituição), disponibilização de relógios (presente em quatro Ilpi, com a ressalva de que em duas delas eles se encontravam na entrada da instituição), e a disponibilização de calendários nos quartos (observada em cinco instituições, com exceção de uma que os disponibilizava somente para idosos independentes). Algumas instituições citadas nesse estudo permitiam que os residentes levassem objetos pessoais, sendo que em duas eles não havia armários individuais e em outra, os armários eram disponibilizados somente para os idosos considerados independentes. Em quatro instituições a roupa era coletiva, ou seja, os idosos não tinham vestuário próprio. Foi observado que a presença de corrimão era frequente nos banheiros e nos corredores. Além disso, as instalações sanitárias eram precárias em duas Ilpi e havia precariedade na provisão de equipamentos de prevenção de quedas (e.g. luz de vigília). Equipamentos de autoajuda, como andadores, aparelhos auditivos ou cadeira de rodas, só foram encontrados em quantidade suficiente em três instituições.

Os artigos descrevem rotinas bastante rígidas dentro das Ilpi, principalmente em relação à alimentação e à higiene corporal. De modo geral, a grande maioria dos artigos relata a oferta de cinco a seis refeições diárias, nas quais havia pouca participação dos idosos na escolha do cardápio. Somente uma instituição fornecia opções substitutivas para as grandes refeições (almoço e jantar). Os horários eram pré-determinados pelas instituições e era comum a utilização de sinos para informar aos residentes o horário do almoço e do jantar. De modo geral, as Ilpi investigadas privilegiavam o período da manhã 
para os banhos e levavam em consideração o nível de dependência dos residentes a fim de que os idosos mais dependentes pudessem ser auxiliados. Apenas uma instituição declarou deixar livres os horários de banho para idosos independentes (Bestetti \& Chiarelli, 2012).

A realização de atividades físicas e de lazer não foi relatada com frequência pelos estudos. Uma Ilpi apresentava uma programação de atividades, porém com baixa adesão dos residentes (Faleiros \& Morano, 2009). Duas instituições permitiam que os idosos mais independentes participassem de eventos externos e grupos de convivência (Cornélio \& Godoy, 2013; Creutzberg et al., 2011), além de ser comum que esses idosos tivessem autorização para se ausentar da instituição durante um período do dia (Creutzberg et al., 2011; Faleiros \& Morano, 2009). A permissão aos idosos com maior capacidade funcional para a realização de tarefas simples dentro da instituição não é habitual, relatada em apenas um estudo (Creutzberg et al., 2011).

Em apenas duas instituições foi relatada a realização de viagens turísticas (Cornélio \& Godoy, 2013; Mansano-Schlosser et al., 2014); em três delas era comum a realização de atividades sociais, tais como aniversários, grupos de convivência, dinâmicas recreativas, passeios com filhos, entre outras (Cornélio \& Godoy, 2013; Creutzberg et al., 2011). As atividades realizadas com menor frequência foram filmes, música, leitura, palavras cruzadas, oficinas de artesanato e crochê.

Cinco artigos classificaram as instituições estudadas (29 Ilpi) como mistas (51\% das instituições), ou seja, recebiam idosos de ambos os sexos; algumas eram exclusivamente femininas (34\%) e duas eram exclusivamente masculinas (7\%). Sete artigos investigaram o número de homens e mulheres residentes nas Ilpi estudadas, todas mistas. Na maioria desses artigos (seis), o número de mulheres era superior ao de homens. A porcentagem de mulheres nas instituições variou entre $38 \%$ e $74 \%$.

Dois artigos (Angelo et al., 2011; Carvalho, 2014) forneceram informações a respeito do grau de dependência dos residentes das respectivas Ilpi participantes, tendo como referencial a RDC no 283/2005 da Anvisa, a qual classifica o Grau de Dependência do Idoso como: a) grau I - idosos independentes, mesmo que necessitem de equipamentos de autoajuda; b) grau II - idosos com dependência em até três atividades de autocuidado para a vida diária (alimentação, mobilidade, higiene), sem comprometimento cognitivo ou com alteração cognitiva controlada; e c) grau III - idosos com dependência que necessitam de assistência em todas as atividades de autocuidado para a vida diária e/ou que apresentam comprometimento cognitivo. Nesses estudos, 242 residentes foram avaliados segundo esses critérios. A maioria dos idosos avaliados (41\%) foram classificados como de grau I (independentes), 33\% apresentaram grau de dependência II e outros $24 \%$ apresentaram grau de dependência III (além de dois residentes que não foram identificados no roteiro de inspeção).

Dois artigos (Bestetti \& Chiarelli, 2012; Yamamoto \& Diogo, 2002) avaliaram o grau de dependência dos idosos, mas não com base na classificação da Anvisa. Yamamoto e Diogo (2002) avaliaram 287 idosos, dos quais $51 \%$ foram classificados como independentes, $37 \%$ como dependentes parciais e $11 \%$ como dependentes totais; Bestetti e Chiarelli (2012) apresentaram essa informação de forma mais geral, descrevendo a presença de idosos independentes, com déficits cognitivos (embora o diagnóstico individual não fosse conhecido), semidependentes (oito cadeirantes) e dependentes (15 acamados). Observa-se, portanto, que a maioria dos idosos residentes nas Ilpi investigadas eram independentes.

Todos os artigos que caracterizam as Ilpi trouxeram informações a respeito da equipe técnica. Vinte e cinco instituições relataram ter médicos, 18 tinham assistentes sociais, 13 tinham serviços de nutrição, 22 informaram a presença de técnicos de enfermagem e uma informou possuir equipe de enfermagem 24 horas por dia. Havia enfermeiros em 21 instituições e fisioterapeutas em 13. Os profissionais menos frequentemente mencionados pelas instituições foram os terapeutas ocupacionais, farmacêuticos, dentistas e psicólogos, os quais, quando presentes, com frequência eram voluntários.

Os artigos de Creutzberg et al. (2011) e Bestetti e Chiarelli (2012) informaram que poucas instituições mantinham o número adequado de cuidadores por residentes de acordo com o grau de dependência, conforme a RDC no 283/2005 (Anvisa, 2005). Cornélio e Godoy (2013) relataram a falta de capacitação para os cuidadores, também mencionada nas demais outras pesquisas, e a sobrecarga de trabalho.

\section{Caracterização de funções psicológicas e cognitivas dos residentes das Ilpi}

Foram encontrados 15 artigos que caracterizavam as condições cognitivas e psicológicas de residentes de Ilpi de forma direta, e outros quatro que 
traziam essas informações de forma indireta, por meio do rastreamento do uso de psicofármacos (total de artigos $=19$ ). Esses estudos foram publicados entre 2009 e 2015. Os objetivos dos 15 primeiros trabalhos se distribuíram de maneira homogênea em torno da caracterização da sintomatologia depressiva e seus fatores associados, além do estado cognitivo dos residentes. Os quatro últimos artigos tinham como objetivos a avaliação do padrão medicamentoso prescrito a idosos residentes em Ilpi, assim como a verificação de interações medicamentosas.

A maioria dos artigos (18) trouxe informações a respeito do número de instituições nas quais os dados foram coletados, totalizando 65 instituições. Elas estavam localizadas nas regiões Sudeste (sete em São Paulo, uma no Rio de Janeiro, 12 em Minas Gerais $\mathrm{n}=20$ ); Centro-Oeste (três em Mato Grosso do Sul, três em Mato Grosso, 12 no Distrito Federal e cinco em Goiás $-\mathrm{n}=23$ ); Nordeste (14 em Pernambuco e uma na Bahia $-\mathrm{n}=15$ ); e Sul (cinco no Paraná e duas no Rio Grande do Sul - n = 7). Não foram encontrados estudos realizados na região Norte.

Os instrumentos mais utilizados para caracterização das funções psicológicas e cognitivas dos idosos foram Escala de Depressão Geriátrica reduzida de Yesavage (GDS-15), Mini-Exame do Estado Mental (MEEM) e Escalas Funcionais de Atividades Básicas de Vida Diária, como o índice de Katz, a escala de Lawton e Brody, índice de Barthel, que também avalia a capacidade funcional do idoso, e a Medida de Independência Funcional (MIF). Menos comumente foram utilizados APGAR de família, entrevistas, Escala de Avaliação de Demência (DRS), diagnóstico clínico, teste de recordação de palavras da bateria Cerad, teste do desenho do relógio e avaliação de depressão pela versão completa da Escala de Depressão Geriátrica (GDS-30).

Para a avaliação dos medicamentos prescritos aos residentes das Ilpi, os pesquisadores dos quatro artigos utilizaram questionários respondidos pelos idosos e pelos cuidadores, formulários e consulta aos prontuários dos idosos. A quantidade de participantes das pesquisas variou entre 60 e 760, com média de 157. O estudo de Menezes et al. (2011) tinha desenho longitudinal e avaliou a mesma amostra de idosos em dois momentos diferentes, com um intervalo de dois anos entre as avaliações, e, por conta disso, apresenta variações em seu número de participantes: no primeiro momento de investigação havia 95 participantes e no segundo momento, 59 .
Houve o predomínio de residentes solteiros (sempre solteiros, divorciados e viúvos), seguido por casados ou com companheiros. Quinze artigos trouxeram informações a respeito do número de homens e mulheres presentes nas instituições, verificando predomínio de residentes do sexo feminino (14). Apenas no estudo de Santiago e Mattos (2014) havia mais homens residentes do que mulheres.

Nos 13 artigos que trouxeram informações a respeito da idade dos residentes, verificou-se que a média de idade dos idosos estava entre 70 e 79 anos. No artigo de Gontijo et al. (2012), a média de idade foi de 78,4 anos, mas nessa instituição prevaleceu a faixa etária de 80 anos ou mais $(47,4 \%)$. Isso também ocorreu no estudo de Fochat et al. (2012), no qual a maioria dos residentes $(55,7 \%)$ tinha 80 anos ou mais.

Dez artigos trouxeram informações a respeito da escolaridade dos residentes. Em todos, a maioria dos idosos era analfabeta ou havia frequentado a escola por poucos anos, ou seja, a maioria dos idosos analisados possuía baixa escolaridade.

Sete artigos apresentaram a avaliação de depressão entre os residentes das Ilpi e informaram uma prevalência de sintomas depressivos em torno de 50\% da amostra. A exceção foi o estudo de Oliveira et al. (2014), no qual $67 \%$ da amostra apresentou sintomas depressivos. No estudo de Lampert e Rosso (2015), $32,3 \%$ da amostra foi diagnosticada com depressão.

Em um estudo longitudinal (Menezes et al., 2011), verificou-se que a utilização da medicação não se alterou na instituição ao longo de dois anos, com exceção do uso de "antidepressivos", que aumentou de forma expressiva, passando de $6,8 \%$ para $18,6 \%$ dos residentes. Em relação à sintomatologia depressiva avaliada nesse estudo, também houve mudanças: na primeira avaliação, $40,7 \%$ dos residentes apresentavam sintomas depressivos e na segunda avaliação, 44,1\%; entretanto, essa diferença não foi estatisticamente significativa.

Os estudos de Lampert e Rosso (2015) e Silva et al. (2012) investigaram se a depressão tinha relação com algum outro componente (gênero, idade, grau de independência ou presença de comorbidades, como ansiedade, esquizofrenia e outras desordens psiquiátricas), mas foram encontradas poucas correlações (das quais as mais importantes estavam relacionadas a gênero, grau de dependência e idade). Os estudos de Oliveira et al. (2014), Silva et al. (2012) e Leal et al. (2014) verificaram a presença 
de correlação estatística entre os sintomas depressivos, estado civil e faixa etária. Silva et al. (2012) verificaram uma associação significativa entre sintomas de depressão e insônia, taquicardia, parestesia, tontura e suor excessivo.

Oliveira et al. (2014) avaliaram a relação entre os sintomas depressivos e a funcionalidade familiar dos idosos institucionalizados. As autoras constataram que a maioria dos idosos com sintomas depressivos também apresentava disfunção familiar. O estudo concluiu que idosos que apresentavam disfunção familiar tinham seis vezes mais chances de apresentar sintomas depressivos que os demais idosos.

A presença de declínio cognitivo e demência também foi muito comum nos idosos estudados, com prevalência que variou entre $45 \%$ e $86 \%$ das amostras. Além disso, o baixo desempenho no MEEM foi frequente. Os estudos de Dantas et al. (2013), Gontijo et al. (2012), e Mello et al. (2012) verificaram que a demência foi a doença que mais causou prejuízos no desempenho funcional dos idosos, devido ao próprio quadro de comprometimento das funções cognitivas provocado pela condição.

Também foi relatada a presença de outras desordens psiquiátricas em menor frequência, como esquizofrenia, transtorno compulsivo obsessivo, esclerose múltipla, transtorno bipolar afetivo e deficiência intelectual (Dantas et al., 2013; Lampert \& Rosso, 2015; Mello et al., 2012). No entanto, os dados coletados sobre essas condições, em geral, foram obtidos em prontuários (Silva et al., 2012). No estudo de Oliveira e Novaes (2012), realizado com 154 idosos, 71 foram considerados "sem discernimento" (sic) e verificou-se que esse grupo de idosos sofria mais com doenças psiquiátricas. Também foi observada forte associação entre a percepção dos idosos em relação à instituição (gostar ou não gostar), a depressão e distúrbios psiquiátricos.

Os artigos que analisaram os medicamentos dos idosos residentes nas instituições realizaram uma caracterização indireta de suas condições psiquiátricas. Todos os estudos descreveram o uso de várias classes de medicamentos (como os antipsicóticos e os psicoanalépticos), mas o dado mais relevante é o trazido pelo estudo de Oliveira e Novaes (2012), segundo o qual $98 \%$ dos idosos utilizavam no mínimo um psicofármaco, dos quais os antipsicóticos, hipnóticos, sedativos, ansiolíticos, antidepressivos e anticonvulsivantes foram os mais relatados.

\section{Discussão}

De modo geral, os resultados obtidos nos diferentes estudos foram muito parecidos, o que sugere que as condições institucionais (estruturais e funcionais) oferecidas para idosos são muito similares nas Ilpi de diferentes regiões do país. Além disso, verificou-se que a prevalência de transtornos como a depressão e a demência apresentada pelos estudos são muito parecidas e altas, um indicativo, também, de uma regularidade entre os diferentes ambientes institucionais analisados. Esses resultados merecem atenção, especialmente ao se considerar as características das Ilpi detalhadas pelos estudos e a necessidade de os profissionais pensarem em intervenções que possam diminuir o sofrimento psíquico de idosos institucionalizados.

Observou-se que o número de instituições estudadas nos artigos revisados representa uma parcela pequena em comparação ao número de Ilpi no Brasil - 41 instituições em um universo de cerca de 3.500 identificadas em 2009 (Instituto de Pesquisa Econômica Aplicada [Ipea], 2011) - e que elas estão concentradas nas regiões Sudeste e Nordeste. Isso demonstra a necessidade de se investir em estudos que possam oferecer mais informações sobre essas instituições, uma vez que elas têm crescido em quantidade em todo o país. Além disso, não foram registrados estudos sobre Ilpi da região Norte. Pode-se entender a concentração dos estudos nas regiões Sudeste e Nordeste, assim como a ausência de estudos na região Norte, em função da própria distribuição de Ilpi no país, levantada pelo estudo de Camarano, Kanso, Mello e Carvalho (2010): cerca de dois terços das Ilpi se encontram na região Sudeste, enquanto a região Norte tem o menor número dessas instituições. Por outro lado, a falta de informações sobre as instituições de uma região do país indica a necessidade de mais informações sobre esse território.

A maioria das instituições estudadas nos artigos revisados era de natureza filantrópica, o que também está de acordo com os resultados discutidos por Camarano et al. (2010). As autoras afirmam que a falta de moradia e condições financeiras precárias são os principais motivos de procura por Ilpi, o que pode explicar a alta porcentagem de instituições filantrópicas no país (65\%), em comparação com instituições privadas (28\%) ou públicas e mistas (7\%). Esse tipo de financiamento provavelmente se reflete nos serviços prestados pelas instituições e em seus quadros de funcionários: a maioria das instituições estudadas apresentava $o$ 
mínimo de funcionários exigidos pela Anvisa (2005), especialmente profissionais de enfermagem de diferentes níveis de formação que possivelmente atuam como cuidadores, além de médicos, assistentes sociais e profissionais ligados à manutenção do espaço físico e da alimentação. Reflete-se, também, na falta de outros profissionais, como psicólogos e fisioterapeutas, muitos dos quais trabalham de forma voluntária. Considerando que mais da metade do orçamento das instituições é destinada ao pagamento de funcionários (Ipea, 2011) e que as equipes dessas instituições costumam ser reduzidas, como mostraram os estudos aqui revisados, pode-se deduzir que essas instituições enfrentam dificuldades na ampliação da oferta de serviços importantes para os idosos.

As consequências de equipes técnicas constituídas de um número reduzido de profissionais podem variar desde dificuldades em manter serviços básicos para os residentes até ausência de condições para lidar com problemas frequentemente encontrados em ambientes institucionais, como o sofrimento psíquico. Sete dos nove artigos revisados sobre os ambientes institucionais fizeram recomendações para a melhoria da qualidade dos serviços oferecidos pelas Ilpi aos seus residentes.

A necessidade de equipes profissionais qualificadas e capacitadas foi citada em todos os artigos, três dos quais destacaram a necessidade de realização de atividades que promovessem a manutenção da capacidade funcional dos idosos e do autocuidado, levando em consideração sua independência para tomar decisões e a interação entre fatores físicos, psicológicos e sociais (Angelo et al., 2011; Cornélio \& Godoy, 2013; Creutzberg et al., 2011). Esses resultados podem ser entendidos como um alerta para que sejam promovidas discussões na sociedade, na academia e entre os profissionais de saúde a respeito da cidadania dos idosos institucionalizados e da garantia de seus direitos quanto ao envelhecimento ativo (WHO, 2005).

Ainda sobre a natureza das instituições pesquisadas, verificou-se um número reduzido de instituições privadas como constituintes das amostras dos estudos. Além disso, as instituições de natureza privada analisadas declaravam formas de captação de recursos semelhantes às de instituições filantrópicas, o que pode sugerir que essas instituições também enfrentam problemas de financiamento. Isso sugere, por um lado, a dificuldade de manutenção dessas instituições em decorrência dos elevados gastos impli- cado na manutenção de Ilpi (Camarano et al., 2010) e, por outro, que são necessários estudos também em instituições privadas em boas condições financeiras a fim de se poder compreender melhor a relação entre as condições financeiras das instituições e as condições físicas e psicológicas de seus residentes.

De modo geral, a caracterização dos idosos residentes nas Ilpi pesquisadas mostrou a predominância de mulheres e de residentes independentes para as atividades diárias. Esse resultado é interessante porque, a princípio, seria possível pensar que o maior grau de dependência é um fator determinante para a institucionalização. É preciso lembrar, porém, que o cuidado de pessoas com alto grau de dependência demanda serviços especializados e de alto custo e que, como visto anteriormente, as instituições, especialmente as de natureza filantrópica, tendem a ter orçamentos limitados.

O ambiente institucional verificado nos estudos foi muito semelhante nas diferentes Ilpi: quartos compartilhados, horários rígidos para as atividades de alimentação e higiene, baixo nível de controle sobre as rotinas e reduzidas opções de lazer. O estudo de Creutzberg et al. (2011) argumenta que esse tipo de ambiente institucional pode contribuir para a perda de autonomia e de independência dos idosos, o que vai no sentido oposto ao que a OMS tem denominado como envelhecimento ativo (WHO, 2005). É fundamental que os arranjos ambientais possam estimular as capacidades físicas e cognitivas do indivíduo para que ele seja capaz de participar das rotinas de sua residência, bem como ser autônomo na tomada de decisões que $\mathrm{o}$ afetam diretamente. Além disso, os profissionais que atuam em Ilpi necessitam de treinamento em práticas que reconheçam as potencialidades dos idosos, estimulando-os a se manter tão independentes quanto possível a fim de melhorar sua qualidade de vida mesmo em ambientes institucionais (WHO, 2005).

O que se verificou nos estudos, porém, foi um alto índice de adoecimento mental entre os residentes de Ilpi. A depressão se apresentou como o quadro clínico mais prevalente entre idosos pesquisados nos estudos revisados, assim como o declínio cognitivo. Outros tipos de sofrimento mental foram relatados em poucos estudos com baixa prevalência, o que pode ser possivelmente explicado pelos próprios critérios de admissão dos idosos nas instituições. A prevalência de depressão encontrada entre idosos institucionalizados (cerca de 50\%) foi maior que os índices encontrados 
na população idosa em geral, que varia entre 15 e 30\% (Gullich, Duro, \& Cesar, 2016; Oliveira, Gomes, \& Oliveira, 2006; Ramos, Carneiro, Barbosa, Mendonça, \& Caldeira, 2015), mas é semelhante a resultados de estudos sobre idosos institucionalizados em Portugal realizados por Leal et al. (2014) e Vaz e Gaspar (2011). Leal et al. (2014) verificaram correlação entre depressão e escolaridade, sexo e estado civil. Vaz e Gaspar (2011) encontraram correlação negativa entre depressão e nível cognitivo, adaptação à vida institucional e importância dada a atividades de lazer; e correlação positiva entre depressão e grau de solidão e de dependência nas atividades de vida diária. Esses resultados são importantes porque, de acordo com Leite, Carvalho, Barreto e Falcão (2006), a depressão encontra-se entre as doenças crônicas que mais aumentam as chances de desenvolvimento de incapacidade funcional.

Além da depressão, os estudos revisados também constataram alta prevalência de comprometimento cognitivo entre os residentes de Ilpi (entre $45 \%$ e 86\%), prevalência maior que a encontrada na população em geral por alguns estudos brasileiros, que relatam taxas entre $18 \%$ e $65 \%$ (Lentsck, Pilger, Schoereder, Prezotto, \& Mathias, 2015; Machado, Ribeiro, Cotta, \& Leal, 2011; Nascimento, Batista, Rocha, \& Vasconcelos, 2015). Tanto os dados de prevalência de depressão quanto os de comprometimento cognitivo devem ser analisados de forma cuidadosa. Não se pode afirmar que a institucionalização em si seja a principal causa desses quadros, a despeito de alguns dados da literatura que afirmam ser o ambiente institucional um importante fator de risco para a ocorrência dessas patologias (Jesus et al., 2010). É possível que a presença anterior desses quadros tenha contribuído de forma decisiva para a institucionalização (Bertoldi, Batista, \& Ruzanowsky, 2015) e que a alta prevalência desses quadros reflita apenas uma condição de risco aumentado para a institucionalização. De qualquer forma, é preciso discutir o papel das Ilpi e de seus profissionais na intervenção sobre esses problemas e na contribuição para a melhoria da qualidade de vida desses idosos institucionalizados, para além do cuidado medicamentoso.

Estudos nacionais e internacionais mostram vários resultados positivos de intervenções, tanto sobre quadros depressivos quanto sobre problemas cognitivos de residentes de Ilpi (Chariglione \& Janczura, 2013; Franck, Molyneux, \& Parkinson, 2016; Karimi et al., 2010; Winningham, \& Pike, 2007). Intervenções desse tipo, porém, demandam profissionais preparados, especialmente psicólogos que tenham conhecimentos suficientes para identificar problemas dessa ordem e analisar as características específicas dos ambientes institucionais para conduzir intervenções adequadas e significativas para os residentes. No entanto, essa necessidade esbarra em duas dificuldades. A primeira delas se refere à pouca atenção que a psicologia, especialmente no Brasil, tem dado às questões concernentes ao envelhecimento (Monteleone \& Witter, 2017). A formação de profissionais de psicologia para o trabalho com idosos deve incluir o desenvolvimento de atitudes interventivas que fomentem a autonomia, habilidades cognitivas, enfrentamento das dificuldades e bom relacionamento social entre os idosos, reconhecendo e explorando a experiência e as possibilidades que esses indivíduos têm para melhorar seu bem-estar (WHO, 2005).

A segunda é de ordem prática e refere-se às dificuldades enfrentadas por Ilpi para manter equipes multiprofissionais capazes de promover o bem-estar e a saúde psicológica dos residentes, como apontado pelos estudos revisados aqui. Pesquisa realizada por Lacerda et al. (2017) em Ilpi da região metropolitana de Belo Horizonte mostra que as instituições filantrópicas dependem muito de doações e de parcerias com o poder público (ainda que essa fonte de financiamento seja pequena) e com instituições de formação (instituições de ensino superior), além do trabalho voluntário, para garantir sua oferta de serviços. Essa situação ilustra bem as dificuldades encontradas por Ilpi para manter-se em funcionamento e oferecer serviços de qualidade aos residentes.

\section{Conclusões}

As Ilpi desempenham um papel importante em uma sociedade que enfrenta mudanças em sua estrutura familiar, e atendem a uma demanda crescente por serviços de qualidade para o atendimento a idosos que dela necessitam. $\mathrm{O}$ aumento do número dessas instituições e da demanda por esse tipo de serviço, porém, deve ser acompanhado por dois conjuntos de ações. Por um lado, é importante que a sociedade supere preconceitos e noções equivocadas sobre $o$ papel das Ilpi e lhe atribua a devida importância no contexto atual, mobilizando-se para a melhoria na qualidade dos serviços dessas instituições. Por outro lado, é preciso aprofundar o conhecimento sobre essas instituições para que seja possível o planejamento de políticas públicas que atendam às necessi- 
dades dos idosos, a fim de que as Ilpi não reproduzam as desigualdades já existentes em nossa sociedade.

A literatura aponta claramente que os idosos em condições de vulnerabilidade socioeconômica (que incluem baixa renda, baixa escolaridade, acesso dificultado a serviços de saúde, rede reduzida de apoio social etc.) são aqueles mais propensos à institucionalização (Pinheiro et al., 2016). Esses idosos constituem o público-alvo de Ilpi públicas e filantrópicas e, como se viu nesta revisão, são aqueles que, apesar de mais precisarem de cuidados, residem em instituições que enfrentam inúmeras dificuldades para sua manutenção e prestação de serviços. De acordo com Giacomin e Couto (2010, p. 215), "no Brasil, as Ilpi não são resultado de uma política pública e sim a marca registrada da sua ausência, guardando uma relação profunda com a filantropia e a religião". É nesse sentido que se espera que o poder público possa capitanear a discussão fundamental, ainda que difícil, sobre o financiamento das instituições de cuidados de longa duração aos idosos e das redes de compartilhamento de cuidados, ainda raras e pouco efetivas no país. O desenvolvimento de ações de cuidado destinadas aos idosos, especialmente àqueles mais vulneráveis, é uma necessidade premente na atualidade.

Outro desafio importante em relação ao envelhecimento e às Ilpi é a formação de profissionais que atendam as demandas de cuidado de longa duração para idosos. Especificamente no tocante à psicologia, o sofrimento psíquico constatado nos estudos aqui revisados indica a urgência de que esta ciência dê maior atenção a tal parcela da população, a fim de contribuir de forma mais efetiva com a melhoria da qualidade de vida de idosos institucionalizados. Os resultados do presente estudo sugerem que as Ilpi assumem um modelo de abrigamento de caráter coletivo, que promove o isolamento e a inatividade dos residentes e necessariamente se constitui como um importante agravo para a manutenção da saúde mental dos idosos. Um olhar para a individualidade desses idosos e para formas de intervir nos ambientes institucionais são contribuições fundamentais que os psicólogos podem oferecer a esse campo de estudo.

\section{Referências}

Agência Nacional de Vigilância Sanitária. (2005, 26 de setembro). $R D C n^{\circ}$ 283, de 26 de setembro de 2005. Normas de funcionamento para as Instituições de Longa Permanência para Idosos. https://bvsms.saude.gov.br/bvs/saudelegis/ anvisa/2005/res0283_26_09_2005.html

Aires, M., Paz, A. P., \& Perosa, C. T. (2009). Situação de saúde e grau de dependência de pessoas idosas institucionalizadas. Revista Gaúcha de Enfermagem, 30(3),492499. https://seer.ufrgs.br/RevistaGauchadeEnfermagem/ article/view/8239/6996

Alencar, M. A., Bruck, N. N. S., Pereira, B. C., Câmara, T. M. M., \& Almeida, R. D. S. (2012). Perfil dos idosos residentes em uma instituição de longa permanência. Revista Brasileira de Geriatria e Gerontologia, 15(4), 785796. http://dx.doi.org/10.1590/S1809-98232012000400017

Angelo, B. H. B., Silva, D. I. B., \& Lima, M. A. S. (2011). Avaliação das instituições de longa permanência para idosos do município de Olinda-PE. Revista Brasileira de Geriatria e Gerontologia, 14(4), 663673. http:// dx.doi.org/10.1590/S1809-98232011000400006

Bertoldi, J. T., Batista, A. C., \& Ruzanowsky, S. (2015). Declínio cognitivo em idosos institucionalizados: Revisão de literatura. Cinergis, 16(2), 152156. http://dx.doi.org/10.17058/cinergis.v16i2.5411

Bestetti, M. L. T., \& Chiarelli, T. M. (2012). Planejamento criativo em instituições de longa permanência para idosos: Estudo de caso em Foz do Iguaçu - PR. Perspectivas em Gestão \& Conhecimento, 2(1), 3651. https:// periodicos.ufpb.br/ojs2/index.php/pgc/article/view/10623/7439

Camarano, A. A., \& Kanso, S. (2010). Como as famílias brasileiras estão lidando com os idosos que demandam cuidados e quais as perspectivas futuras? A visão mostrada pelas PNADS. In A. A. Camarano (Ed.), Cuidados de longa duração para a população idosa: Um novo risco social a ser assumido? (pp. 93122). Ipea.

Camarano, A. A., \& Mello, J. L. (2010a). Cuidados de longa duração no Brasil: O arcabouço legal e as ações governamentais. In A. A. Camarano (Ed.), Cuidados de longa duração para a população idosa: Um novo risco social a ser assumido? (pp. 6791). Ipea. 
Camarano, A. A., \& Mello, J. L. (2010b). Introdução. In A. A. Camarano (Ed.), Cuidados de longa duração para a população idosa: Um novo risco social a ser assumido? (pp. 1337). Ipea.

Camarano, A. A., Kanso, S., Mello, J. L., \& Carvalho, D. F. (2010). As instituições de longa permanência para idosos no Brasil. In A. A. Camarano (Ed.), Cuidados de longa duração para a população idosa: Um novo risco social a ser assumido? (pp. 187-212). Ipea.

Carlomanho, A. M. F., Soares, E., \& Carvalho, S. M. R. (2013). Declínio cognitivo e depressão em idosos institucionalizados e não institucionalizados: Possibilidades de correlação. Revista de Iniciação Científica da FFC, 13(3), 123. https://doi.org/10.36311/1415-8612.2013.v13n3.2791

Carvalho, V. L. D. (2014). Perfil das instituições de longa permanência para idosos situadas em uma capital do Nordeste. Cadernos de Saúde Coletiva, 22(2), 184-191. https:// doi.org/10.36311/1415-8612.2013.v13n3.2791

Chariglione, I. P. F., \& Janczura, G. A. (2013). Contribuições de um treino cognitivo para a memória de idosos institucionalizados. Psico-USF, 18(1), 1322. http://dx.doi.org/10.1590/S1413-82712013000100003

Cornélio, G. F., \& Godoy, I. D. (2013). Perfil das instituições de longa permanência para idosos em uma cidade no estado de São Paulo. Revista Brasileira de Geriatria e Gerontologia, 16(3), 559568. http://dx.doi.org/10.1590/ S1809-98232013000300013

Creutzberg, M., Gonçalves, L. H. T., Santos, B. L., Santos, S. S. C., Pelzer, M. T., Portella, M. R., Scortegagna, H. M., Rodrigues, R. A. P., Marques, S., Sales, Z. N., Alvarez, A. M., Schier, J., Sena, E. L. S., Meira, E. C., \& Souza, A. S. (2011). Acoplamento estrutural das instituições de longa permanência para idosos com sistemas societais do entorno. Revista Gaúcha de Enfermagem, 32(2), 219225. http://dx.doi.org/10.1590/S1983-14472011000200002

Dantas, H. L. C. M., Bello, F. A., Barreto, K. L. L., \& Lima, L. S. (2013). Capacidade funcional de idosos com doenças crônicas residentes em Instituições de Longa Permanência. Revista Brasileira de Enfermagem, 66(6), 914920. https://doi.org/10.1590/S0034-71672013000600016

Ervatti, L. R., Borges, G. M., \& Jardim, A. P. (Orgs.). (2015). Mudança demográfica no Brasil no início do século XXI: Subsídios para as projeções da população. IBGE. http://biblioteca.ibge.gov.br/visualizacao/livros/liv93322.pdf

Faleiros, V. D. P., \& Morano, T. (2009). Cotidiano e relações de poder numa instituição de longa permanência para pessoas idosas. Textos \& Contextos, 8(2), 319338. https://repositorio.unb.br/bitstream/10482/9086/1/ ARTIGO_CotidianoRelacoesPoder.pdf

Ferreira, L. S., Pinho, M. S. P., Pereira, M. W. M., \& Ferreira, A. P. (2014). Perfil cognitivo de idosos residentes em Instituições de Longa Permanência de Brasília-DF. Revista Brasileira de Enfermagem, 67(2), 247251. https:// dx.doi.org/10.5935/0034-7167.20140033

Fochat, R. C., Horsth, R. B. O., Sette, M. S., Raposo, N. R. B., \& Chicourel, E. L. (2012). Perfil de utilização de medicamentos por idosos frágeis institucionalizados na Zona da Mata Mineira, Brasil. Revista de Ciências Farmacêuticas Básica e Aplicada, 33(3), 447454. https://rcfba.fcfar.unesp.br/index.php/ojs/article/view/283/281

Franck, L., Molyneux, N., \& Parkinson, L. (2016). Systematic review of interventions addressing social isolation and depression in aged care clients. Quality of Life Research, 25(6), 13951407. https://doi.org/10.1007/s11136-015-1197-y

Gautério, D. P., Santos, S. S. C., Pelzer, M. T., Barros, E. J., \& Baumgarten, L. (2012). Caracterização dos idosos usuários de medicação residentes em instituição de longa permanência. Revista da Escola de Enfermagem da USP, 46(6), 13941399. http://dx.doi.org/10.1590/S0080-62342012000600016

Giacomin, K. C., \& Couto, E. C. (2010). A fiscalização das ILPIs: O papel dos conselhos, do Ministério Público e da Vigilância Sanitária. In A. A. Camarano (Ed.), Cuidados de longa duração para a população idosa: Um novo risco social a ser assumido? (pp. 213248). Ipea.

Gontijo, V. J., Penha, D. S. G., Fonseca, A. R., \& Augusto, V. G. (2012). Cognitive and functional status of elderly people of a long stay institution of the municipality Divinópolis, Minas Gerais State, Brazil. Acta Scientiarum Health Sciences, 34(spe.), 251256. https:// doi.org/10.4025/actascihealthsci.v34ispec.11938

Gullich, I., Duro, S. M. S., \& Cesar, J. A. (2016). Depressão entre idosos: Um estudo de base populacional no Sul do Brasil. Revista Brasileira de Epidemiologia, 19(4), 691701. https://doi.org/10.1590/1980-5497201600040001

Hartmann Jr., J. A. S., \& Gomes, G. C. (2015). Sintomatologia depressiva e comprometimento cognitivo de idosos institucionalizados. Revista da SBPH, 18(1), 5281. http://pepsic.bvsalud.org/pdf/rsbph/v18n1/v18n1a04.pdf 
Instituto de Pesquisa Econômica Aplicada. (2011). Infraestrutura social e urbana no Brasil: Subsídios para uma agenda de pesquisa e formulação de políticas públicas. Condições de funcionamento e infraestrutura das instituições de longa permanência para idosos no Brasil. https://www.ipea.gov.br/portal/images/stories/PDFs/ comunicado/110524_comunicadoipea93.pdf

Instituto Brasileiro de Geografia e Estatística. (2018, 25 de julho). Projeção da População 2018: número de habitantes do país deve parar de crescer em 2047. https://agenciadenoticias.ibge.gov.br/agencia-sala-de-imprensa/ 2013-agencia-de-noticias/releases/21837-projecao-da-populacao-2018-numero-de-habitantes-do-pais-deve-parar-de-crescer-em-2047

Jacinto, A. F., Aguiar, A. C. P. O., Franco, F. G. M., Ribeiro, M. I., \& Citero, V. A. (2012). Estudo psicométrico da Escala de Avaliação de Demência e sua aplicabilidade em instituições de longa permanência no Brasil. Einstein, 10(3), 318322. https://doi.org/10.1590/S1679-45082012000300011

Jesus, I. S., Sena, E. L. S., Meira, E. C., Gonçalves, L. H. T., \& Alvarez, A. M. (2010). Cuidado sistematizado a idosos com afecção demencial residentes em instituição de longa permanência. Revista Gaúcha de Enfermagem, 31(2), 28592. https://doi.org/10.1590/S1983-14472010000200012

Karimi, H., Dolatshahee, B., Momeni, K., Khodabakhshi, A., Rezaei, M., \& Kamrani, A. A. (2010). Effectiveness of integrative and instrumental reminiscence therapies on depression symptoms reduction in institutionalized older adults: An empirical study. Aging \& Mental Health, 14(7), 881887. https://doi.org/10.1080/13607861003801037

Lacerda, T. T. B., Horta, N. C., Souza, M. C. M. R., Oliveira, T. R. P. R., Marcelino, K. G. S., \& Ferreira, Q. N. (2017). Caracterização das instituições de longa permanência para idosos da região metropolitana de Belo Horizonte. Revista Brasileira de Geriatria e Gerontologia, 20(6), 743753. https://dx.doi.org/10.1590/1981-22562017020.170014

Lampert, M. A., \& Rosso, A. L. P. (2015). Depression in elderly women resident in a long-stay nursing home. Dementia \& Neuropsychologia, 9(1), 7680. http://dx.doi.org/10.1590/S1980-57642015DN91000012

Leal, M. C. C., Apóstolo, J. L. A., Mendes, A. M. O. C., \& Marques, A. P. O. (2014). Prevalência de sintomatologia depressiva e fatores associados entre idosos institucionalizados. Acta Paulista de Enfermagem, 27(3), 208214. http://dx.doi.org/10.1590/1982-0194201400036

Lei n. 10.741, de $1^{\circ}$ de outubro de 2003. (2003, 3 de outubro). Dispõe sobre o Estatuto do Idoso e dá outras providências. Diário Oficial da União. http://www.planalto.gov.br/ccivil_03/leis/2003/110.741.htm

Leite, V. M. M., Carvalho, E. M. F. D., Barreto, K. M. L., \& Falcão, I.V. (2006). Depressão e envelhecimento: Estudo nos participantes do Programa Universidade Aberta à Terceira Idade. Revista Brasileira de Saúde Materno-Infantil, 6(1), 3138. https://doi.org/10.1590/S1519-38292006000100004

Lentsck, M. H., Pilger, C., Schoereder, E. P., Prezotto, K. H., \& Mathias, T. A. F. (2015). Prevalência de sintomas depressivos e sinais de demência em idosos na comunidade. Revista Eletrônica de Enfermagem, 17(3), 19. https://revistas.ufg.br/fen/article/view/34261/20752

Machado, J. C., Ribeiro, R. C. L., Cotta, R. M. M., \& Leal, P. F. G. (2011). Declínio cognitivo de idosos e sua associação com fatores epidemiológicos em Viçosa, Minas Gerais. Revista Brasileira de Geriatria e Gerontologia, 14(1), 109121. http://dx.doi.org/10.1590/S1809-98232011000100012

Mansano-Schlosser, T. C., Santos, A. A., Camargo-Rossignolo, S. C., Freitas, D. C. C. V., Lorenz, V. R., \& Ceolim, M. F. (2014). Idosos institucionalizados: Organização cronológica das rotinas diárias e qualidade do sono. Revista Brasileira de Enfermagem, 67(4), 610616. http://dx.doi.org/10.1590/0034-7167.2014670417

Mattos, I. E., Carmo, C. N., Santiago, L. M., \& Luz, L. L. (2014). Factors associated with functional incapacity in elders living in long stay institutions in Brazil: A cross-sectional study. BMC Geriatrics, 14(1), 47. https:// doi.org/10.1186/1471-2318-14-47

Mello, B. L., Haddad, M. C. L., \& Dellaroza, M. S. G. (2012). Avaliação cognitiva de idosos institucionalizados. Acta Scientiarum. Health Sciences, 34(1), 95102. http://dx.doi.org/10.4025/actascihealthsci.v34i1.7974

Menezes, R. L., Bachion, M. M., Souza, J. T., \& Nakatani, A. Y. K. (2011). Estudo longitudinal dos aspectos multidimensionais da saúde de idosos institucionalizados. Revista Brasileira de Geriatria e Gerontologia, 14(3), 485496. http://dx.doi.org/10.1590/S1809-98232011000300009

Monteleone, T. V., \& Witter, C. (2017). Prática baseada em evidências em Psicologia e idosos: Conceitos, estudos e perspectivas. Psicologia: Ciência e Profissão, 37(1), 4861. http://dx.doi.org/10.1590/1982-3703003962015 
Nascimento, R. A. S., Batista, R. T. S., Rocha, S. V., \&Vasconcelos, L. R. C. (2015). Prevalência e fatores associados ao declínio cognitivo em idosos com baixa condição econômica: Estudo MONIDI. Jornal Brasileiro de Psiquiatria, 64(3), 187192. http://dx.doi.org/10.1590/0047-2085000000077

Nóbrega, I. R. A. P., Leal, M. C. C., Marques, A. P. O., \& Vieira, J. C. M. (2015). Fatores associados à depressão em idosos institucionalizados: revisão integrativa. Centro Brasileiro de Estudos de Saúde, 39(105), 536550. https:// doi.org/10.1590/0103-110420151050002020

Oliveira, D. A., Gomes, L., \& Oliveira, R. F. (2006). Prevalência de depressão em idosos que frequentam centros de convivência. Revista de Saúde Pública, 40(4), 734736. https://doi.org/10.1590/S0034-89102006000500026

Oliveira, M. P. F, \& Novaes, M. R.C. G. (2012). Uso de medicamentos por idosos de instituições de longa permanência, Brasília-DF, Brasil. Revista Brasileira de Enfermagem, 65(5), 737744. http://dx.doi.org/10.1590/S0034-71672012000500004

Oliveira, S. C., Santos, A. A., \& Pavarini, S. C. I. (2014). Relação entre sintomas depressivos e a funcionalidade familiar de idosos institucionalizados. Revista da Escola de Enfermagem da USP, 48(1), 6672. http://dx.doi.org/10.1590/ S0080-623420140000100008

Passos, J. P., \& Ferreira, K. S. (2010). Caracterização de uma instituição de longa permanência para idosos e avaliação da qualidade nutricional da dieta oferecida. Alimentos e Nutrição, 21(2), 241249. http://serv-bib.fcfar.unesp. $\mathrm{br} / \mathrm{seer} / \mathrm{index} . \mathrm{php} /$ alimentos/article/view/1027/a10v21n2.pdf

Pinheiro, N. C. G., Holanda, V. C. D., Melo, L. A., Medeiros, A. K. B., \& Lima, K. C. (2016). Desigualdade no perfil dos idosos institucionalizados na cidade de Natal, Brasil. Ciência \& Saúde Coletiva, 21(11), 33993405. https://doi. org/10.1590/1413-812320152111.19472015

Ramos, G. C. F., Carneiro, J. A., Barbosa, A. T. F., Mendonça, J. M. G., \& Caldeira, A. P. (2015). Prevalência de sintomas depressivos e fatores associados em idosos no norte de Minas Gerais: Um estudo de base populacional. Jornal Brasileiro de Psiquiatria, 64(2), 122131. https://doi.org/10.1590/0047-2085000000067

Reis, L. A., Torres, G. V., Araújo, C. C., Reis, L. A., \& Novaes, L. K. N. (2009). Rastreamento cognitivo de idosos institucionalizados no município de Jequié-BA. Psicologia em Estudo, 14(2), 295301. https://doi.org/10.1590/ S1413-73722009000200010

Santiago, L. M., \& Mattos, I. E. (2014). Depressive symptoms in institutionalized older adults. Revista de Saúde Pública, 48(2), 216224. http://dx.doi.org/10.1590/S0034-8910.2014048004965

Silva, E. R., Sousa, A. R. P., Ferreira, L. B., \& Peixoto, H. M. (2012). Prevalência e fatores associados à depressão entre idosos institucionalizados: Subsídio ao cuidado de enfermagem. Revista da Escola de Enfermagem da USP, 46(6), 13881394. http://dx.doi.org/10.1590/S0080-62342012000600015

Smanioto, F. N., \& Haddad, M. C. L. (2013). Avaliação da farmacoterapia prescrita a idosos institucionalizados. Revista Brasileira de Enfermagem, 66(4), 523527. http://dx.doi.org/10.1590/S0034-71672013000400009

Souza, M. T., Silva, M. D., \& Carvalho, R. (2010). Revisão integrativa: O que é e como fazer. Einstein, 8(1), 102106. http://dx.doi.org/10.1590/s1679-45082010rw1134

Souza, P. D., Beneditti, T. R. B., Borges, L. J., Mazo, G. Z., \& Gonçalves, L. H. T. (2011). Aptidão funcional de idosos residentes em uma instituição de longa permanência. Revista Brasileira de Geriatria e Gerontologia, 14(1), 716. http://dx.doi.org/10.1590/S1809-98232011000100002

Vaz, S. F. A., \& Gaspar, N. M. S. (2011). Depressão em idosos institucionalizados no distrito de Bragança. Referência - Revista de Enfermagem, 3(4), 4958. http://dx.doi.org/10.12707/RIII1124

Winningham, R. G., \& Pike, N.L. (2007). A cognitive intervention to enhance institutionalized older adults' social support networks anddecreaseloneliness. Aging\&MentalHealth, 11(6),716721.https://doi.org/10.1080/13607860701366228

World Health Organization. (2005). Envelhecimento ativo: Uma política de saúde. Organização Pan-Americana da Saúde. https://bvsms.saude.gov.br/bvs/publicacoes/envelhecimento_ativo.pdf

World Health Organization. (2015). World report on ageing and health. WHO Press. https://apps.who.int/iris/bitstream/handle/10665/186463/9789240694811_eng.pdf

Yamamoto, A., \& Diogo, M. J. D. (2002). Os idosos e as instituições asilares do município de Campinas. Revista Latino-Americana de Enfermagem, 10(5), 660666. http://dx.doi.org/10.1590/S0104-11692002000500006 


\section{Raísa Abrantes Penna}

Psicóloga formada pela Universidade de São Paulo (USP), Ribeirão Preto - SP. Brasil.

E-mail: raisaabrantes@gmail.com

(1) https:// orcid.org/0000-0001-8473-8093

\section{Andréia Schmidt}

Doutora em Psicologia Experimental e docente da Universidade de São Paulo (USP), Ribeirão Preto - SP. Brasil.

E-mail: aschmidt@ffclrp.usp.br

(1) https://orcid.org/0000-0002-8836-6618

Endereço para envio de correspondência:

Andréia Schmidt. Faculdade de Filosofia, Ciências e Letras de Ribeirão Preto (FFCLRP), Departamento de Psicologia. Av. Bandeirantes, 3900, Monte Alegre. CEP: 14040-901. Ribeirão Preto - SP. Brasil.

Recebido 19/02/2018

Aceito 31/01/2019

Received 02/19/2018

Approved 01/31/2019

Recibido 19/02/2018

Aceptado 31/01/2019

Como citar: Penna, R. A., \& Schmidt, A. (2021). Práticas de psicólogos na estratégia Saúde da Família: Instituições Residenciais Brasileiras para Idosos e Condições Psicológicas e Cognitivas de Residentes. Psicologia: Ciência e Profissão, 41 (n.spe 4), 1-20. https://doi.org/10.1590/1982-3703003191768

How to cite: Penna, R. A., \& Schmidt, A. (2021). Brazilian Long-Term Care Institutions and Psychological and Cognitive Conditions of Residents. Psicologia: Ciência e Profissão, 41 (n.spe 4), 1-20.

https://doi.org/10.1590/1982-3703003191768

Cómo citar: Penna, R. A., \& Schmidt, A. (2021). Los Hogares para Ancianos en Brasil y las Condiciones Psicológicas y Cognitivas de sus Residentes. Psicologia: Ciência e Profissão, 41 (n.spe 4), 1-20. https://doi.org/10.1590/1982-3703003191768 